\title{
Experimental study on a small scale of gas hydrate cold storage apparatus
}

\author{
Yingming Xie ${ }^{\mathrm{a}, *}, \mathrm{Gang} \mathrm{Li}^{\mathrm{a}}$, Daoping Liu ${ }^{\mathrm{a}}$, Ni Liu ${ }^{\mathrm{a}}$, Yingxia Qi ${ }^{\mathrm{a}}$, Deqing Liang ${ }^{\mathrm{b}}$, Kaihua Guo ${ }^{\mathrm{b}}$, Shuanshi Fan ${ }^{\mathrm{b}}$ \\ ${ }^{a}$ School of Energy \& Power Engineering, University of Shanghai for Science and Technology, Shanghai, PR China \\ ${ }^{\mathrm{b}}$ Guangzhou Institute of Energy Conversion, The Chinese Academy of Sciences, Guangzhou, PR China
}

\section{A R T I C L E I N F O}

\section{Article history:}

Received 29 December 2008

Received in revised form 26 May 2010

Accepted 31 May 2010

Available online 6 July 2010

\section{Keywords:}

Gas hydrate

Cold storage

Heat exchanger

SDS

Hydration enhancement

Coolant

\begin{abstract}
A B S T R A C T
To have an overall investigation of cold storage characteristics to help to promote the application, a novel small scale of gas hydrate cold storage apparatus was designed. The amount of cold energy, growth rate, Hydrate Packed Factor (HPF) and overall heat transfer coefficient during the cold storage process were calculated and analyzed under different heat exchangers, sodium dodecyl benzene sulfonate (SDS) concentrations, hydration enhancement ways, inlet coolant temperatures and flow rates, etc. Results show that the cold storage performance could be improved greatly by adding a heat exchanger with vertical metal fins; SDS with concentration of 0.04 wt.\% could help to improve the cold storage performance effectively. In addition, decreasing of the coolant temperature or increasing of the coolant flow rate could also make the amount of cold storage increased; it was found that mechanical blending for 5 min was the better hydration enhancement way than others, which presents the perspective for practical application.
\end{abstract}

(c) 2010 Elsevier Ltd. All rights reserved.

\section{Introduction}

Nowadays, with the onset of energy crisis, thermal energy storage is a relatively new technology with growing interest for a large number of thermal applications, including cooling in buildings for air-conditioning system. Many new thermal energy storage systems [1-4], phase change materials [5], and new ways of optimization [6-8] for storage systems have been proposed. Even though lots of energy storage-relative work has been done by previous researchers, cold storage technology, especially the gas hydrate cold storage technology, is still need to pay more attention for its great potential for application.

Gas hydrates, also called clathrate hydrates, are ice-like crystals, which are composed of host lattice(cavities) formed by water molecules linking with each other through hydrogen bonding, and other guest molecules. The guest molecules are firmly enclosed inside the host cavities under weak van de Waals force. A large variety of gases or volatile liquids can form clathrate hydrates with water under certain conditions of temperature and pressure, such as natural gases, $\mathrm{CO}_{2}$ and many kinds of freon refrigerants [9]. Some gas hydrates can be considered as one of the most promising phase change materials for cold storage in air-conditioning systems for proper phase-change temperature range $\left(4-20^{\circ} \mathrm{C}\right)$, and large fusion heat $(270-430 \mathrm{~kJ} / \mathrm{kg})$. When compared with ice cold

\footnotetext{
* Corresponding author. Address: School of Energy \& Power Engineering, University of Shanghai for Science and Technology, No. 516 Jungong Rd., Shanghai 200093, PR China. Tel./fax: +86 2155270305.

E-mail address: xymbox@sina.com (Y. Xie).
}

storage system, gas hydrate system can make the refrigeration efficiency improved greatly with the help of chilled water as circulation medium rather than antifreeze coolant or brine, and the conventional water chillers instead of the expensive ice maker for application. With a larger fusion heat than ice or eutectic salt, the gas hydrate can also decrease the volume of cold storage tank and the cost for the initial investment [10].

Special interest has spawned a wealth of ideas regarding their significance in air-conditioning since this novel cold storage technology was first proposed by Tomlinson [11] in 1982. It is necessary to mention that the following research institutes have done great efforts and gained outstanding achievement in this area: the Oak Ridge Laboratory, USA [12], the National Chemical Laboratory for Industry, Japan [13], and Dept. of Mechanical Engineering, Keio University, Japan [14]. Several Chinese institutes also made great contribution, such as the Guangzhou Institute of Energy Conversion, the Chinese Academy of Sciences [15], and the Chemical Engineering Institute, South China University of Technology [16].

While, the practical application of the new technology is hampered by a serial of harsh conditions and one of the major problems is the poor dissolubility for refrigerants in water, which decreases the hydration formation rate. In fact, only a thin film of hydrates is formed at the interface between water and hydrophobic guest phases without mechanical stirring tested by many experiments. Although the hydrate formation can be improved greatly by mechanical stirring, it is at the expense of additional energy along with the increased initial investment and maintenance costs. Furthermore, the amount of free interstitial water in the formed gas hydrates increased by the stirring can decrease the compact degree 
of the formed gas hydrates, which leads to the decrease of the amount of unit cold energy [17].

Yutaka [18] found that $\mathrm{CO}_{2}$ gas hydrate can grow along the solid surface of high polar surface free energy without stirring. Xie $[19,20]$ constructed a set of visual gas hydrate reaction apparatus and researched the gas hydrate formation process outside a single heat transfer tube in a quiescent reactor. It was found that gas hydrates can grow continuously along the heat transfer tube without stirring, from which a novel way for gas hydrate steady formation was presented-gas hydrate fast nucleation from melting ice and quiescent growth along heat transfer tube [21]. In addition, Ohmura et al. [22] studied the mechanism of hydrate crystals in liquid water in contact with a hydrophobic hydrate-forming liquid, Sun et al. [23] and Bi et al. [24] made a further research on influences of additives for hydrate formation, and Bi et al. [25] also studied the influence of volumetric-flow rate for the formation progress.

In order to have a more systematic and overall research on the practical characteristics of gas hydrate cold storage to promote the application better, a small scale of gas hydrate cold storage apparatus with inner heat exchanger and outer crystallization pump was designed to conduct corresponding experimental study, as shown in Fig. 1.

\section{Experimental apparatus and procedure}

\subsection{Experimental apparatus}

As shown in Fig. 1a, this gas hydrate cold storage system consists of five main subsystems: a cold storage tank with interior heat exchanger and exterior crystallization pump (Cold storage tank), refrigeration system (Water chiller), cold release system (Fan coil unit), and data measurement $\&$ acquisition system (Temperature transducers, Flow meter), etc.

The diagram of the cold storage tank, which is made of stainless steel, with the inner length, width, and height of $0.72 \mathrm{~m}, 0.31 \mathrm{~m}$, $0.72 \mathrm{~m}$ respectively, is shown in Fig. 1b. Its cubage is about $0.16 \mathrm{~m}^{3}$. There is a flange equipped on one side of the cold storage tank, which can be dismantled to make it possible that different kinds of heat exchangers can be mounted into the tank to test the cold storage performance. Two borosilicate glass vision windows with the inner diameter of $0.15 \mathrm{~m}$ are mounted at the front face and the back one of the tank respectively, through which the cold storage process inside the tank can be observed. An operation valve is mounted on the top of the tank, through which water, refrigerant and additives can be charged into the tank. Four temperature measurement points and one pressure measurement one are distributed on side and top faces of the tank. Red copper heat exchanger (bare pipe type or vertical metal fins enhanced type) in the tank has seven inlets and outlets respectively, and the pipes are arranged in triangle, with the outer diameter of $10 \mathrm{~mm}$ and thickness of $1 \mathrm{~mm}$ respectively. The diameters of inlet and outlet manifold are both $22 \mathrm{~mm}$. The coolant flow directions in two neighboring pipes are opposite to ensure the temperature of the tank even. A discharge valve is equipped at the bottom of the tank to facilitate the cleaning of tank and replace cold storage medium. A crystallization pump (crystallizer) is mounted on the outside of the tank, which can accelerate the hydration process by mechanically blending refrigerant and water from two connected pipes: one pipe is inserted into the liquid refrigerant phase, and the other into the liquid water phase.

The refrigeration unit is a set of water chiller with power of 3P, which can chill coolant down to the lowest temperature of $-5^{\circ} \mathrm{C}$.

The cold release system is composed of KF-23GW fan coil unit, and BJZ-50 stainless flow injection pump. Air volume of the fan coil unit is about $370 \mathrm{~m}^{3} / \mathrm{h}$, and the cooled air is directly released to the lab space. The delivery pressure and flow rate of the injection pump are $15 \mathrm{mH}_{2} \mathrm{O}$ and $30 \mathrm{~L} / \mathrm{min}$ respectively.

The data measurement and acquisition system is composed of a set of Agilent 34970A acquisition system, a set of PC, six Pt-100 resistance thermometers, LWGY-15B/TBS turbine flow sensor, a set of pressure meter, a set of vacuum gauge, and a set of electric steelyard, etc.

Main dates (temperature and flow rate) recorded in the progress of hydrate formation are listed as follows:

Inlet and outlet temperatures of the heat exchanger: Two Pt-100 resistance thermometers are mounted in inlet and outlet respectively to get the difference of temperature between inlet and outlet of the heat exchanger.

Temperatures in cold storage tank: Three Pt-100 resistance thermometers are respectively fixed at the height of $63 \mathrm{~mm}$, $112 \mathrm{~mm}$, and $363 \mathrm{~mm}$ from the bottom of the tank to measure the temperature of liquid refrigerant phase, water-refrigerant interface, and superjacent waters phase respectively. By observ-

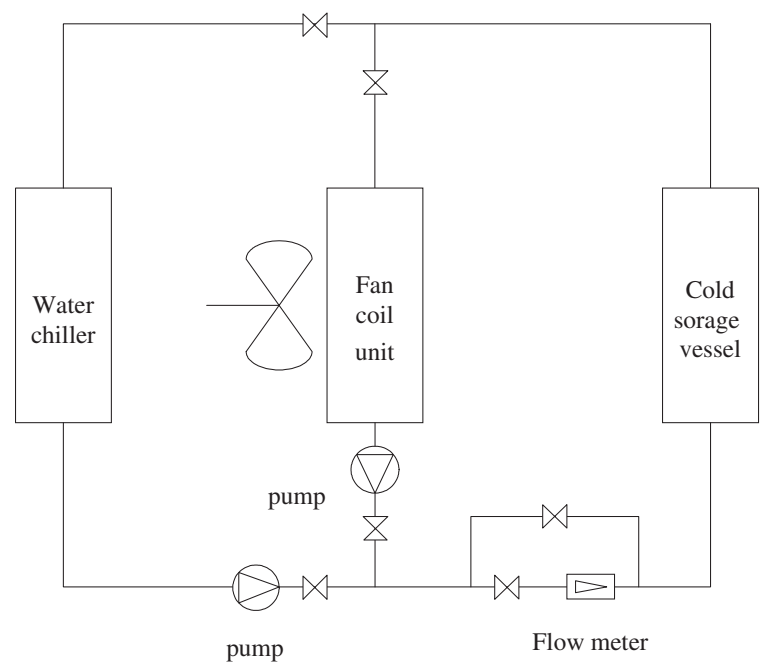

(a) General system diagram

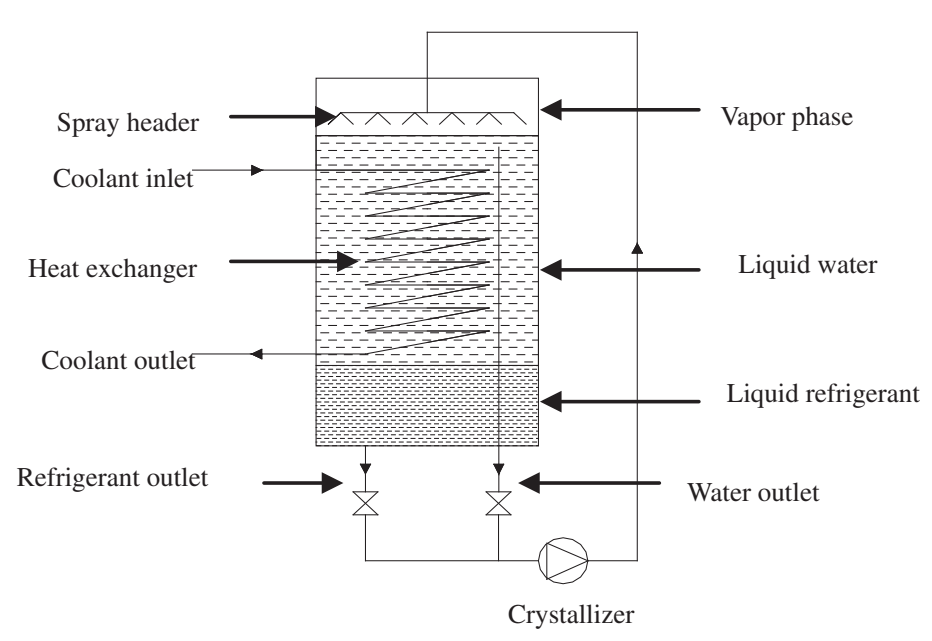

(b) Diagram of cold storage vessel

Fig. 1. Diagram of gas hydrate cold storage system. 
ing the variation of these temperatures, judgment could be made on whether the reaction process within the cold storage tank had occurred or been completed.

Coolant flow rate in heat exchanger: During the process of cold storage and cold release, coolant flow rate in heat exchanger is measured by flow meter, and cold storage/cold release rate and total amount of cold energy could be calculated in combination with the inlet and outlet temperatures of the heat exchanger.

All dates for each group had been tested several times to ensure the accuracy for better analysis.

\subsection{Experiment materials and heat exchangers}

In view of the pressure tolerance of cold storage tank, in this study only the cold storage performance of low pressure HCFC$141 \mathrm{~b}$ hydrate was tested. Based on hydration reaction theory the ideal mass ratio of HCFC-141b and water is $1: 2.62$ to make the reaction rationally. In this study, the mass of refrigerant is $20 \mathrm{~kg}$, and water is $80 \mathrm{~kg}$, which exceeded the above ratio a little to ensure the HCFC-141b could be reacted completely. HCFC-141b with its purity of more than $99.5 \%$ is bought from French AlliedSignal Corporation. Heat exchangers in the study are classified into two types: bare pipe heat exchanger (with heat exchange area of about $5.4 \mathrm{~m}^{2}$ ) and heat exchanger enhanced by vertical aluminum fins (the distance between fins is $1 \mathrm{~cm}$, and the heat exchange area is about $9 \mathrm{~m}^{2}$ ). To make hydrate cold storage technology more practical, all the sample of the water in this study is tap water.

\subsection{Uncertainty analysis}

Temperature values are the major parameters measured in this research. All temperature sensors used in this research are in top measurement accuracy (to allow error within $\pm 0.15^{\circ} \mathrm{C}$ ), and they transfer signal to data acquisition system using four-wire connection to minimize measurement errors caused by line resistance. Before the formal experiment, all temperature sensors are calibrated by water bath (temperature accuracy is within $\pm 0.1{ }^{\circ} \mathrm{C}$ ) and standard mercury thermometer in the temperature range of -10 to $20^{\circ} \mathrm{C}$. Calibration results showed that each temperature sensor' max error is less than $0.2^{\circ} \mathrm{C}$.

\subsection{Experimental procedure}

The experimental procedure for hydrate reaction in this study was listed as follows:

(1) Charging reaction substances: Cold storage tank was cleaned by tap water before all tests, and then certain amounts of tap water and liquid HCFC-141b was charged into the tank through the valve at the top of tank.

(2) Cold storage process: Cold storage valves were opened along with the water chiller turned on, coolant in water chiller flowed through heat exchanger to cool the tank, and then the cold storage process began. At the same time, the data measurement \& acquisition system was turned on to measure the coolant flow rate, and record the temperatures inside the tank and the temperatures at the inlet and outlet of the heat exchanger.

(3) Cold release process: When cold storage tank temperature decreased rapidly, which indicated that cold storage process had been completed, it is time for cold release process. At the same time, water chiller and cold storage valves were shut off, cold release valves were opened, the fan coil unit and injection pump were turned on to release cold energy, and temperatures in cold storage tank and at the inlet and outlet of heat exchanger during the cold release process were recorded, as well as the coolant flow rate.

Six groups of experiments were listed in Table 1.

\section{Theoretical analysis}

\subsection{Calculation of cold energy amount}

Considering cold storage tank as a control volume, the energy equation could be expressed as the following formula:

$Q_{s}=\int_{0}^{\tau} C_{f} \dot{m}_{f}\left(T_{f, \text { out }}-T_{f, \text { in }}\right) d \tau-\bar{U}_{k} \int_{0}^{\tau}\left(T_{\text {sur }}-T_{w}\right) d \tau$

$C_{f}$ is the specific heat of coolant, and assumed to be constant value, $\mathrm{kJ} /(\mathrm{kg} \mathrm{K})$; Therefore

$Q_{s}=C_{f} \dot{m}_{f} \int_{0}^{\tau}\left(T_{f, \text { out }}-T_{f, \text { in }}\right) d \tau-\bar{U}_{k} \int_{0}^{\tau}\left(T_{\text {sur }}-T_{w}\right) d \tau$

or

$Q_{s}=C_{f} \dot{m}_{f} \sum_{i=1}^{n}\left(T_{f, o u t, i}-T_{f, i n, i}\right) \Delta \tau_{i}-\bar{U}_{k} \sum_{i=1}^{n}\left(T_{\text {sur }, i}-T_{w, i}\right) \Delta \tau_{i}$

where $\dot{m}_{f}$ is the average flow rate, $\mathrm{kg} / \mathrm{min} ; T_{f, \text { out }}$ and $T_{f, \text { in }}$ are the outlet and inlet temperature of the coolant, $\mathrm{K} ; \overline{U_{k}}$ is the heat transfer coefficient from tank to the ambient; $T_{s u i, i}$ and $T_{w, i}$ are the instant temperature of ambient and tank respectively, $\mathrm{K} ; \Delta \tau_{i}$ is the measurement time spacing, min.

\subsection{Calculation of average gas hydrate growth velocity and HPF}

Average hydrate growth velocity is defined as the mean hydration velocity during the hydration process, that is:

$\overline{v_{h}}=\frac{\int_{0}^{\tau_{h}} v_{h} d \tau}{\tau_{h}}=\frac{1}{344} \frac{Q_{h}}{\tau_{h}}$

where $Q_{h}$ is the total latent heat of hydration, $\mathrm{kJ} ; \tau_{h}$ is the total hydration time, min.

Imitating a common parameter of IPF in ice cold storage system, a new parameter Hydrate Packed Factor (HPF) is created here, which is defined as the ratio of hydrate mass to total mass of HCFC-141b and water before reaction:

$\mathrm{HPF}=\frac{M_{h}}{M_{0}} \times 100 \%$

where $M_{h}$ is the mass of formed hydrate, $\mathrm{kg}$ and $M_{0}$ is the mass of total reaction materials, $\mathrm{kg}$.

To simple the results for better analysis, the unit changed for $Q_{s}$ and $Q_{h}$ is $\mathrm{MJ}$ in all figures and tables.

\subsection{Calculation of general heat transfer coefficient}

General heat transfer equation on heat exchanger during cold storage process is formulated as:

$K_{s} F \overline{\Delta T_{l m}}=\frac{Q_{s}}{\tau_{s}}$

So general heat transfer coefficient $K_{s}\left(\mathrm{~kW} /\left(\mathrm{m}^{2} \mathrm{~K}\right)\right)$ is:

$K_{s}=\frac{Q_{s}}{F \overline{\Delta T_{l m}} \tau_{s}}$

where $\tau_{s}$ is the time taken by hydration process, $\mathrm{min} ; \Delta T_{l m}$ is logarithm average temperature difference between inside and outside of the heat exchanger, $\mathrm{K} ; \overline{\Delta T_{l m}}$ is an average value of $\Delta T_{l m}$ during 
Table 1

Experimental groups under different conditions.

\begin{tabular}{|c|c|c|c|c|c|c|}
\hline $\begin{array}{l}\text { Test } \\
\text { groups }\end{array}$ & Heat exchanger & $\begin{array}{l}\text { Hydration enhancement } \\
\text { ways }\end{array}$ & $\begin{array}{l}\text { Coolant temperature } \\
\text { in cold storage } \\
\text { process }\left({ }^{\circ} \mathrm{C}\right)\end{array}$ & $\begin{array}{l}\text { Coolant flow rate in } \\
\text { cold storage process } \\
(\mathrm{L} / \mathrm{h})\end{array}$ & $\begin{array}{l}\text { SDS } \\
\text { concentration } \\
\text { (wt.\%) }\end{array}$ & Experiment objective \\
\hline I & $\begin{array}{l}\text { Bare pipe heat } \\
\text { exchanger }\end{array}$ & $\begin{array}{l}\text { Mechanical blending } \\
\text { continuously }\end{array}$ & 2 & 1200 & 0 & $\begin{array}{l}\text { Acquire the fundamental } \\
\text { characteristics of cold storage process }\end{array}$ \\
\hline II & $\begin{array}{l}\text { Heat exchanger } \\
\text { with vertical } \\
\text { metal fins }\end{array}$ & $\begin{array}{l}\text { Mechanical blending } \\
\text { continuously }\end{array}$ & 2 & 1200 & 0 & $\begin{array}{l}\text { Study characteristics of cold storage } \\
\text { process when vertical metal fins used }\end{array}$ \\
\hline III & Same as group II & $\begin{array}{l}\text { Mechanical blending } \\
\text { continuously }\end{array}$ & 2 & 1200 & $\begin{array}{l}0.01,0.02,0.04 \\
0.06\end{array}$ & $\begin{array}{l}\text { Study the effect of SDS on cold storage } \\
\text { process }\end{array}$ \\
\hline IV & Same as group II & $\begin{array}{l}\text { Mechanical blending for } \\
5 \text { min, fast hydration from } \\
\text { melting ice }\end{array}$ & 2 & 1200 & $\begin{array}{l}\text { The optimum } \\
\text { value from } \\
\text { group III }\end{array}$ & $\begin{array}{l}\text { Study the effect of different hydration } \\
\text { enhancement methods on cold storage } \\
\text { process }\end{array}$ \\
\hline V & Same as group II & $\begin{array}{l}\text { Mechanical blending for } \\
5 \text { min }\end{array}$ & $2,4,6$ & 1200 & $\begin{array}{l}\text { Same as group } \\
\text { IV }\end{array}$ & $\begin{array}{l}\text { Study the effect of different coolant } \\
\text { temperatures on cold storage process }\end{array}$ \\
\hline VI & Same as group II & $\begin{array}{l}\text { Mechanical blending for } \\
5 \mathrm{~min}\end{array}$ & 2 & $400,600,800,1200$ & $\begin{array}{l}\text { Same as group } \\
\text { IV }\end{array}$ & $\begin{array}{l}\text { Study the effect of different coolant } \\
\text { flow rates on cold storage process }\end{array}$ \\
\hline
\end{tabular}

the whole hydration process, $\mathrm{K}$; and $F$ is the area of the heat exchanger, $\mathrm{m}^{2}$.

\section{Experiment results and discussion}

\subsection{Fundamental cold storage characteristics (results of experimental groups I and II)}

When cold storage process started, crystallizer was turn on. Two types of pipe heat exchanger were conduct, and it was found that the curve shape of average temperature in the cold storage tank were same. Typical curve of average temperature in tank using bare pipe heat exchanger during the cold storage process was showed in Fig. 2, in which curve AB represented growth process of gas hydrate. The results of experimental groups I and II were showed in Table 2. It could be observed that at the beginning

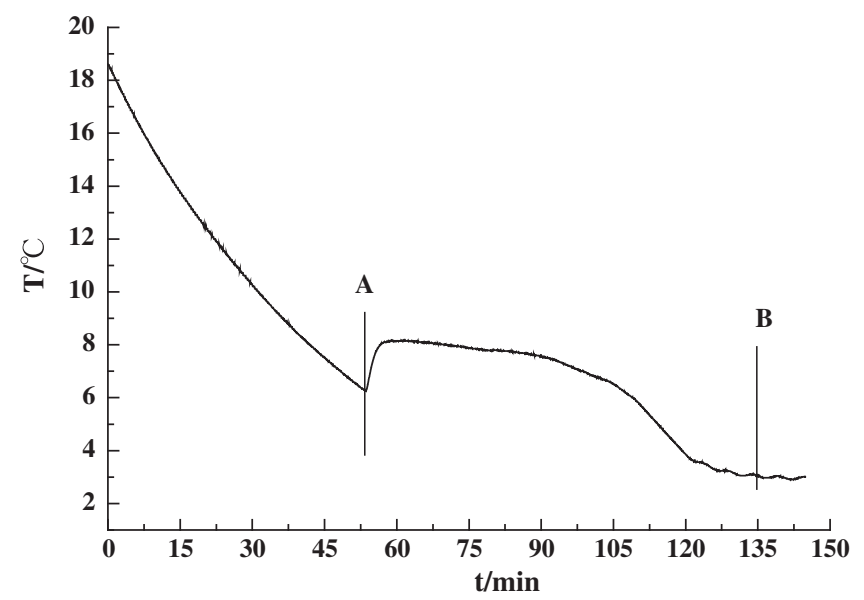

Fig. 2. Typical average temperature in the tank using bare pipe heat exchanger during cold storage process. the dropping liquid drips were milky because of the mixture of water and HCFC-141b for nucleation, and then the reaction proceeded rapidly: some muddy liquid drips dropped downward, which expelled heat to upper coils and crystallized further, and then solid into liquids below, or adhered to upper coils. With the progress of hydration, liquid surface went down, and hydrate became compact. When temperature in cold storage tank decreased to point $\mathrm{A}$ as showed in Fig. 2, large scale hydration began, and the solution became clear gradually. Over a period of time, large pile of hydrates on coils could be observed clearly. During this process hydrates formed quickly, and HCFC-141b was consumed rapidly. From the intense rise of temperature at point $A$, it can be easily concluded that hydrates formed fiercely, releasing a great deal of heat. When temperature in cold storage tank reached to point $B$, the hydration process was almost completed. It was found that the formed hydrate did not attach on coils surface as ice did, the horizontal sides of coils appeared bald, and large quantities of hydrates were in the clearance between upper and lower coils.

The analysis of experiment results indicated that the cold energy amount, hydrate growth velocity and general heat transfer coefficient were higher in the type of heat exchanger with vertical metal fins than that with bare pipe, so heat exchanger with vertical metal fins was used in the rest experiments (from group III to group VI).

\subsection{Effect of SDS concentration (results of experimental group III)}

The results for cold storage characteristics under different SDS concentrations were shown in Table 3 and Fig. 3. The results show that, the cold energy amount, growth speed, HPF and general heat transfer coefficient increased sharply by adding SDS. The value of each characteristic parameter increased along with the increase of SDS concentration when SDS concentration was less than $0.04 \%$; while it changed slightly with SDS concentration higher than $0.04 \%$. The general heat exchange coefficient varied abnormally sometimes, which probably was caused by the calculation error of hydration reaction time. Thereby, it is possible that when

Table 2

Results of experimental groups I and II.

\begin{tabular}{|c|c|c|c|c|c|}
\hline \multirow[t]{2}{*}{ Experimental group } & \multicolumn{2}{|c|}{ Cold energy amount $Q_{s}(\mathrm{MJ})$} & \multirow{2}{*}{$\begin{array}{l}\text { Average hydrate growth } \\
\text { velocity } \overline{v_{h}}(\mathrm{~kg} / \mathrm{min})\end{array}$} & \multirow[t]{2}{*}{ HPF (\%) } & \multirow{2}{*}{$\begin{array}{l}\text { General heat transfer } \\
\text { coefficient } K_{s}\left(\mathrm{~kW} /\left(\mathrm{m}^{2} \mathrm{~K}\right)\right.\end{array}$} \\
\hline & $\begin{array}{l}\text { Total cold storage } \\
\text { amount } Q_{s}\end{array}$ & $\begin{array}{l}\text { Latent heat storage } \\
\text { amount } Q_{h}\end{array}$ & & & \\
\hline I & 11.2 & 5.8 & 0.2404 & 16.8 & 0.0656 \\
\hline II & 18.8 & 8.6 & 0.3665 & 25.0 & 0.0858 \\
\hline
\end{tabular}


Table 3

Results of experimental group III.

\begin{tabular}{|c|c|c|c|c|c|}
\hline \multirow[t]{2}{*}{ SDS concentration (\%) } & \multicolumn{2}{|c|}{ Cold energy amount $Q_{s}(\mathrm{MJ})$} & \multirow{2}{*}{$\begin{array}{l}\text { Average hydrate growth } \\
\text { velocity } \overline{v_{h}}(\mathrm{~kg} / \mathrm{min})\end{array}$} & \multirow[t]{2}{*}{$\operatorname{HPF}(\%)$} & \multirow{2}{*}{$\begin{array}{l}\text { General heat transfer } \\
\text { coefficient } K_{s}\left(\mathrm{~kW} /\left(\mathrm{m}^{2} \mathrm{k}\right)\right)\end{array}$} \\
\hline & $\begin{array}{l}\text { Total cold storage } \\
\text { amount } Q_{s}\end{array}$ & $\begin{array}{l}\text { Latent heat storage } \\
\text { amount } Q_{h}\end{array}$ & & & \\
\hline 0.01 & 20.6 & 10.8 & 0.4588 & 31.4 & 0.0896 \\
\hline 0.02 & 26.7 & 16.2 & 0.5686 & 47.1 & 0.0912 \\
\hline 0.04 & 27.2 & 17.1 & 0.5876 & 49.7 & 0.0846 \\
\hline 0.06 & 26.8 & 16.9 & 0.5824 & 49.1 & 0.0853 \\
\hline
\end{tabular}

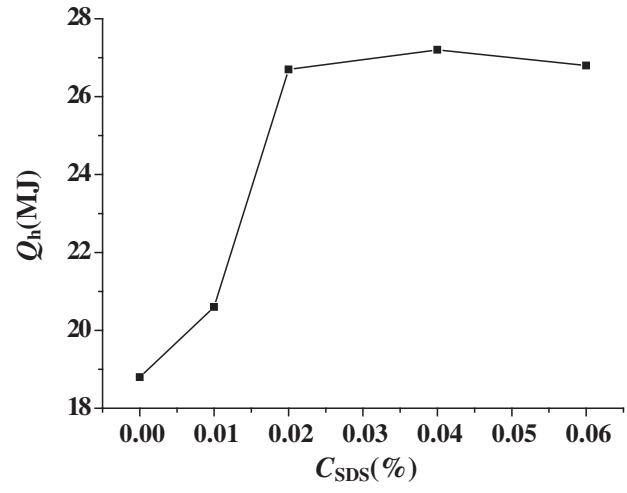

(a) Effect of $C_{S D S}$ on $Q_{\mathrm{h}}$

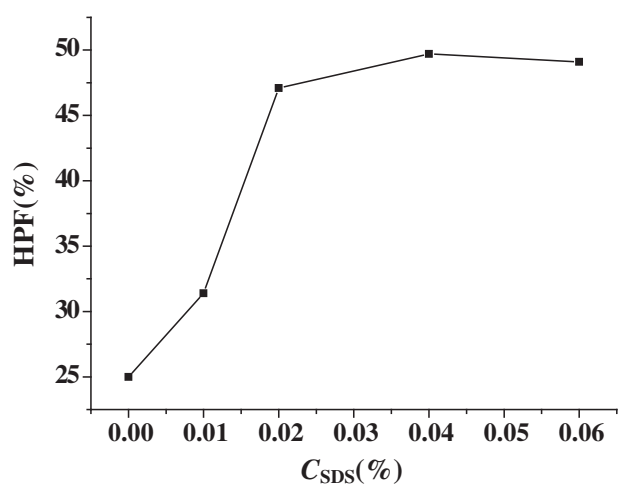

(c) Effect of $C_{S D S}$ on HPF

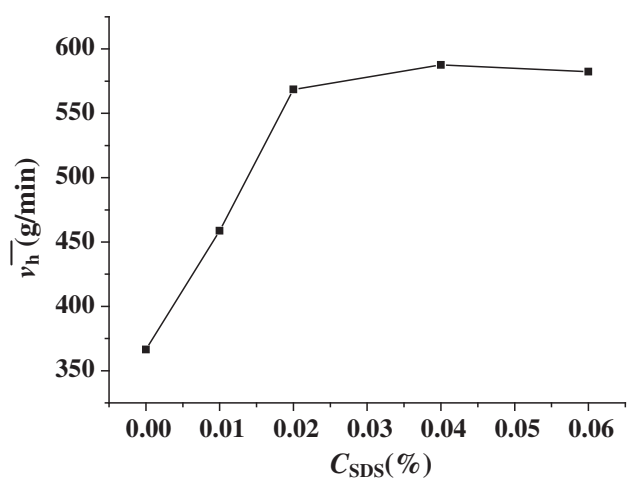

(b) Effect of $C_{S D S}$ on $\overline{v_{h}}$

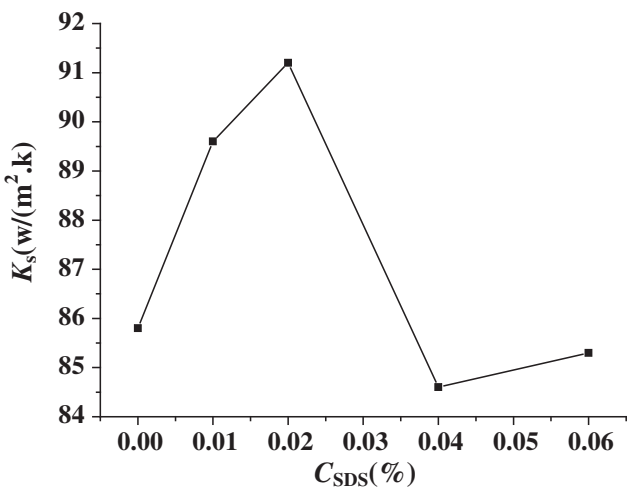

(d) Effect of $C_{S D S}$ on $K_{\mathrm{s}}$

Fig. 3. Effect of SDS Concentration $C_{\mathrm{SDS}}(\%)$ on the cold storage characteristics.

Table 4

Results of experimental group IV.

\begin{tabular}{|c|c|c|c|c|c|}
\hline \multirow[t]{2}{*}{ Hydration enhancement way } & \multicolumn{2}{|c|}{ Cold storage amount $Q_{s}(\mathrm{MJ})$} & \multirow{2}{*}{$\begin{array}{l}\text { Average hydrate growth } \\
\text { velocity } \overline{v_{h}}(\mathrm{~kg} / \mathrm{min})\end{array}$} & \multirow[t]{2}{*}{$\operatorname{HPF}(\%)$} & \multirow{2}{*}{$\begin{array}{l}\text { General heat transfer } \\
\text { coefficient } K_{s}\left(\mathrm{~kW} /\left(\mathrm{m}^{2} \mathrm{k}\right)\right)\end{array}$} \\
\hline & $\begin{array}{l}\text { Total cold storage } \\
\text { amount } Q_{s}\end{array}$ & $\begin{array}{l}\text { Latent heat storage } \\
\text { amount } Q_{h}\end{array}$ & & & \\
\hline Continuous mechanical blending & 27.2 & 17.1 & 0.5876 & 49.7 & 0.0846 \\
\hline Mechanical blending for $5 \mathrm{~min}$ & 23.4 & 12.6 & 0.3052 & 36.6 & 0.0722 \\
\hline Fast hydration from melting ice & 15.6 & 5.4 & 0.2863 & 15.7 & 0.0565 \\
\hline
\end{tabular}

SDS concentration was $0.04 \%$, the system had best cold storage performances, so the rest experiments were done (from group IV to group VI) with $0.04 \%$ SDS concentration.

\subsection{Effect of hydration enhancement methods (results of experimental group IV)}

The results for cold storage characteristics in different hydration enhancement ways were showed in Table 4. Explanations may be given particularly: continuous mechanical blending means that when temperature in cold storage tank falls to the minimum value, crystallizer will be turned on until the finish of cold storage process; mechanical blending for 5 min means that when temperature in cold storage tank falls to the minimum value, crystallizer will be turned on for $5 \mathrm{~min}$, and then stopped again; fast nucleation from melting ice means that the coolant will be cooled to $-5^{\circ} \mathrm{C}$ first, making water in cold storage tank freezed, and then the coolant temperature was increased to $2{ }^{\circ} \mathrm{C}$. So that gas hydrate would generate quickly under the inducement of melting ice. 
Table 5

Results of experimental group V.

\begin{tabular}{|c|c|c|c|c|c|}
\hline \multirow[t]{2}{*}{ Inlet coolant temperature $\left({ }^{\circ} \mathrm{C}\right)$} & \multicolumn{2}{|c|}{ Cold energy amount $Q_{s}(\mathrm{MJ})$} & \multirow{2}{*}{$\begin{array}{l}\text { Average hydrate growth } \\
\text { velocity } \overline{v_{h}}(\mathrm{~kg} / \mathrm{min})\end{array}$} & \multirow[t]{2}{*}{ HPF (\%) } & \multirow{2}{*}{$\begin{array}{l}\text { General heat transfer } \\
\text { coefficient } K_{s}\left(\mathrm{~kW} /\left(\mathrm{m}^{2} \mathrm{k}\right)\right)\end{array}$} \\
\hline & $\begin{array}{l}\text { Total cold storage } \\
\text { amount } Q_{s}\end{array}$ & $\begin{array}{l}\text { Latent heat storage } \\
\text { amount } Q_{h}\end{array}$ & & & \\
\hline 2 & 23.4 & 12.6 & 0.3052 & 36.6 & 0.0722 \\
\hline 4 & 16.6 & 6.8 & 0.2985 & 19.8 & 0.0567 \\
\hline 6 & 8.2 & 3.5 & 0.1655 & 10.2 & 0.0325 \\
\hline
\end{tabular}

Table 6

Results of experimental group VI.

\begin{tabular}{|c|c|c|c|c|c|}
\hline \multirow[t]{2}{*}{ Coolant flow rate $(\mathrm{L} / \mathrm{h})$} & \multicolumn{2}{|c|}{ Cold energy amount $Q_{s}(\mathrm{MJ})$} & \multirow{2}{*}{$\begin{array}{l}\text { Average hydrate growth } \\
\text { velocity } \overline{v_{h}}(\mathrm{~kg} / \mathrm{min})\end{array}$} & \multirow[t]{2}{*}{ HPF (\%) } & \multirow{2}{*}{$\begin{array}{l}\text { General heat transfer } \\
\text { coefficient } K_{s}\left(\mathrm{~kW} /\left(\mathrm{m}^{2} \mathrm{k}\right)\right)\end{array}$} \\
\hline & $\begin{array}{l}\text { Total cold storage } \\
\text { amount } Q_{s}\end{array}$ & $\begin{array}{l}\text { Latent heat storage } \\
\text { amount } Q_{h}\end{array}$ & & & \\
\hline 400 & 14.4 & 8.1 & 0.2263 & 23.5 & 0.0376 \\
\hline 600 & 17.5 & 9.2 & 0.2367 & 26.7 & 0.0516 \\
\hline 800 & 19.6 & 10.6 & 0.2644 & 30.8 & 0.0672 \\
\hline 1200 & 23.4 & 12.6 & 0.3052 & 36.6 & 0.0722 \\
\hline
\end{tabular}

According to the analysis of Table 4, it can be found that all characteristic parameter values were highest in cold storage process in the way of continuous mechanic blending, middle in the way of mechanic blending for $5 \mathrm{~min}$, and lowest in the way of fast nucleation from melting ice. Therefore, the way of continuous mechanical blending had the best cold storage enhancement effect. But, the most energy would be consumed under continuous mechanical blending, and after a long time operation, all connecting components in cold storage system trends to be loosen, which can cause the leakage of cold storage medium. So mechanical blending for 5 min was regarded as the most practical and valuable method, and the rest experiments (the groups V and VI) would be done in this hydration enhancement way. As to why the method of fast nucleation from melting ice had the worst cold storage characteristics, the main reason may be that the whole cold storage process was carried out in quiescent state, which reduced the heat transfer efficiency greater than other two ways. However, fast nucleation from melting ice could avoid a series of problems such as high cost, instability of the system, which were caused by the movement of the crystallizer, so if some methods can be found to improve its heat transfer efficiency more effectively in the future, this way would have a great practical value.

\subsection{Effect of inlet coolant temperature (results of experimental group V)}

The results for cold storage characteristics under different inlet coolant temperatures $\left(2,4\right.$, and $6{ }^{\circ} \mathrm{C}$ respectively) were showed in Table 5 . Analysis indicated that all characteristic parameter values increased with the decrease of inlet coolant temperature. When the inlet coolant temperature was $6^{\circ} \mathrm{C}$, the cold storage amount was only one-third of that when inlet coolant temperature was $2{ }^{\circ} \mathrm{C}$. Therefore, in order to increase cold storage amount, coolant temperature should be decreased as low as possible. However, the lower the inlet coolant temperature, the lower the refrigeration system running efficiency was. So the coolant temperature of $2{ }^{\circ} \mathrm{C}$ was most appropriate, and the rest experiments (the group $\mathrm{VI}$ ) would be done under the coolant temperature of $2^{\circ} \mathrm{C}$.

\subsection{Effect of coolant flow rate (results of experimental group VI)}

The results for cold storage characteristics under different coolant flow rate $(400,600,800,1200 \mathrm{~L} / \mathrm{h}$, respectively) were showed in Table 6. Analysis indicated that all characteristic parameter val- ues increased with the increase of coolant flow rate. The main reason was that when coolant flow rate increased, the flow velocity of coolant in heat exchanger would increase to make the heat transfer coefficient improved. Therefore, in order to increase cold storage amount, coolant flow rate should be increased as high as possible.

\section{Conclusions}

In this paper, the amount of cold storage, the hydrate growth velocity, the HPF and the general heat transfer coefficient, etc. were tested and calculated in a set of gas hydrate cold storage apparatus with an inner heat exchanger and an outer crystallizer, in which HCFC-141b hydrates was used as the cold storage medium. The effects of SDS concentration, the hydration enhancement ways (continuous mechanical blending, mechanical blending for $5 \mathrm{~min}$, and fast nucleation from melting ice), the inlet coolant temperature and the flow rate on the characteristic parameters were discussed and studied. The experiment results indicated that the using of the heat exchanger with vertical metal fins instead of the bare pipe heat exchanger could improve cold storage performance greatly, and adding of SDS with concentration of $0.04 \mathrm{wt} . \%$ could improve cold storage performance further. In addition, the decreasing of the inlet coolant temperature or the increasing of the coolant flow rate could also increase the cold energy. Researches on three hydration enhancement ways showed that continuous mechanical blending has the best cold storage effect, but would lead to extra power consumption and apparatus malfunction; the method of fast nucleation from melting ice has the worst effect, but did not require the running of crystallizer, which is worth to be studied further; the cold storage effect of mechanical blending for $5 \mathrm{~min}$ ranked in a middle position, and it was the best practical hydration enhancement method in this study, which is more valuable for practical application at present.

\section{Acknowledgements}

This work was supported by the National Natural Science Foundation of China (No. 50806050) and the Shanghai Leading Academic Discipline Project (No. S30503).

\section{References}

[1] Ge YT, Tassou SA, Chaer I, Suguartha N. Performance evaluation of a trigeneration system with simulation and experiment. Appl Energy 2009;86:2317-26. 
[2] Zhai H, Dai YJ, Wu JY, Wang RZ. Energy and energy analyses on a novel hybrid solar heating, cooling and power generation system for remote areas. Appl Energy 2009;86:1395-404.

[3] Voyiatzis E, Palyvos JA, Markatos NC. Heat-exchanger design and switchingfrequency effects on the performance of a continuous type solar adsorption chiller. Appl Energy 2008;85:1237-50.

[4] Mawire A, McPherson M, van den Heetkamp RRJ, Mlatho SJP. Simulated performance of storage materials for pebble bed thermal energy storage (TES) systems. Appl Energy 2009;86:1246-52.

[5] Diaconu BM, Varga S, Oliveira AC. Experimental assessment of heat storage properties and heat transfer characteristics of a phase change material slurry for air conditioning applications. Appl Energy 2010;87:620-8.

[6] Lee WS, Chen YT, Wu TH. Optimization for ice-storage air-conditioning system using particle swarm algorithm. Appl Energy 2009;86:1589-95.

[7] Kusiak A, Li M. Cooling output optimization of an air handling unit. Appl Energy 2010;87:901-9.

[8] Al-Sanea SA, Zedan MF. Optimized monthly-fixed thermostat-setting scheme for maximum energy-savings and thermal comfort in air-conditioned spaces. Appl Energy 2008;85:326-46.

[9] Dividson DW. Clathrate hydrates. In: Franks F, editor. Water - a comprehensive treatise, vol. II. New York: Plenum Press; 1973. p. 115-48.

[10] Xie YM, Liang DQ, Guo $\mathrm{KH}$, et al. Advances of gas hydrate cool storage technology. HV\& AC (China) 2004;34:25-8,70.

[11] Tomlinson JJ. Heat pump cool storage in a clathrate of Freon. In: Proc of the 17th IECEC, vol. 4 ; 1982. p. 2060-4.

[12] Ternes MP. Studies on the R-12 gas hydrate formation process for heat pump cool storage application. In: Proc of DOE physical and chemical energy storage annual contractor's review meeting; 1983. CONF-830974.

[13] Akiya T, Tomio S, Oowa M. Phase equilibria of some alternative refrigerants hydrates and their mixtures using for cool storage material. In: Proc of the 32nd IECEC, vol. 4; 1997. p. 1652-5.
[14] Mori T, Mori YH. Characterization of gas hydrate formation in direct-contact cool storage process. Int J Refrig 1989;12:259-65.

[15] Guo KH, Shu BF, Zhao YL. Characterization of phase change and cool-storage process of mixed gas hydrate. In: Proc of ICCR'98, Hangzhou, China; 1998. p. 345-8.

[16] Lu SS, Wang SP, Deng SJ. Experimental study R134a gas hydrate as a cool storage medium. J Refrig 1998;2:1-4.

[17] Zhong Y, Rogers RE. Surfactant effects on gas hydrate formation. Chem Eng Sci 2000;55:4175-87.

[18] Yutaka T, Shuichiro $\mathrm{H}$, Ken O. Massive $\mathrm{CO}_{2}$ clathrate hydrate growth at a highpolar-energy surface. J Cryst Growth 2000;220:180-4.

[19] Xie YM, Guo KH, Liang DQ, et al. Steady gas hydrate growth along vertical heat transfer tube without stirring. Chem Eng Sci 2005;60:777-86.

[20] Xie YM, Guo KH, Liang DQ et al. Gas hydrate growth morphology outside of horizontal heat transfer tube. J Cryst Growth 2005;276:253-64.

[21] Xie YM, Guo KH, Liang DQ, et al. Gas hydrate fast nucleation from melting ice and quiescent growth along vertical heat transfer tube. Sci China B Chem 2005;48:75-82.

22] Ohmura R, Shigetomi $\mathrm{T}$, Mori $\mathrm{YH}$. Formation, growth and dissociation of clathrate hydrate crystals in liquid water in contact with a hydrophobic hydrate-forming liquid. J Cryst Growth 1999;196:164-73.

[23] Sun ZG, Wang RZ, et al. Effect of surfactants and liquid hydrocarbons on gas hydrate formation rate and storage capacity. Int J Energy Res 2003;27:747-56.

[24] Bi YH, Guo TW, Zhu TY, et al. Influences of additives on the gas hydrate cool storage process in a new gas hydrate cool storage system. Energy Convers Manage 2006;47:2974-82.

[25] Bi YH, Guo TW, Zhu TY, Fan SS, Liang DQ, Zhang L. Influence of volumetric-flow rate in the crystallizer on the gas-hydrate cool-storage process in a new gashydrate cool-storage system. Appl Energy 2004;78:111-21. 